\title{
Application Of Wikis With Scaffolding Structure In Laboratory Reporting
}

\author{
Changfeng Ge, Rochester Institute of Technology, USA
}

\begin{abstract}
This work demonstrates how a Wiki can be mapped into different learning stages during groupbased lab reporting via an adequate scaffolding structure. The scaffolding structure of the Wikibased group report is comprised of six constructs in sequence: Appendix, Methods, Results, Analysis, Introduction and Conclusion. The scaffolding structure was developed with the intention of integrating a cooperative learning element into the Wiki's collaborative learning platform. A case study based on a Mechanical Engineering Technology (MET) lab was presented in the study to describe in detail how the group lab report was developed with the Dashboard Wiki. The Wiki compiled data from 42 group reports and student feedback. Lab observations were collected to determine if the Wiki with scaffolding structure, as an instructional tool, had a positive impact on student learning.
\end{abstract}

Keywords: Wikis; Scaffolding Structure; Student Learning; Laboratory Reporting

\section{INTRODUCTION}

¿ n engineering technology courses, the laboratory is an essential component of the curriculum that provides the opportunity for students to blend lecture content with hands-on experiments. Students are often grouped in teams to conduct the laboratory, analyze the data, and write a report. The team-based laboratory is necessary due to constraints on the turnaround time of equipment, and more importantly, for students to gain a greater depth of understanding through interactive learning which individual work cannot support (Cooper and Robinson 1998). Similarly, group-based research projects provide students an opportunity to share research findings.

Despite the importance of the group-based teaching activities in both the laboratory and project, two main challenges exist for the instructor; how to measure the contribution of individual students to the group report and how to enhance experiential learning for every student involved in the group activities. Laboratory reports often lack continuity between paragraphs due to different writing and formatting styles among team members. Peer review is a common tool to assess each student's contribution to the group project. Surprisingly, few students felt that peer reviews were helpful to provide fair input; only one student in a twenty-four student class (mechanical engineering fall, 2010) agreed that peer review is fair and objective.

In conventional group report writing, students put together a report without any proper sequence, and report development depends on the students' individual progress and assignments. The laboratory session for some group members may become the end of the learning cycle when they are assigned to write a section of the report that is not strongly connected to laboratory results, such as the introduction section.

Recently, educators in science and engineering fields have started to use Wiki and blogs as education tools (Elgort,Smith and Toland 2008; Elliott and Fraiman 2010; Heys 2007) . Wiki, a component of WEB 2.0, offers learners and instructors an easily edited shared online platform for co-writing a document. This social software is believed to be particularly suitable for collaborative learning environments, including group projects (Maha 2009). Wikis can store every change the user makes to the document as long as the user is permitted to login on the designated website. Instructors can trace who edited the page and when the change was made. Peers can also view and edit the documents made by other team members. A Wiki can obviously provide the instructor with a platform 
to monitor each student's effort in report writing, which partly helps the instructor to measure an individual's contribution to report writing.

Elliott and Fraiman (2010) reported that using CHEM-Wiki proved successful in allowing students to map their knowledge in a unique, nonlinear way by using hyperlinks in Wikis in a chemical class. The ease of continually updating student-constructed glossaries is especially beneficial in the CHEM-Wiki. The success of the CHEM-Wiki is largely due to the inquiry and research based nature of the chemistry laboratory. Students are required to have intensive discussion and conduct research on the experiments. The CHEM-Wiki provided an ideal platform for students to fulfill their needs. Heys (2007) concluded that Wikis have advantages and disadvantages over the traditional oral and paper mediums in engineering education. The advantages include the ability to continually monitor and measure the work being done by each group and each individual student, as well as straightforward methods for archiving the projects and making them available to future classes.

While there is general agreement among instructors that the instructor would benefit from Wikis when grading the individual contribution to report writing (Puente 2009; Serbec et. al 2010), students have given mixed feedback on the effectiveness of applying Wikis, originally intended to act as social software, to engineering education. Maha (2009) reported that students in software engineering agreed that Wikis improved their teamwork and interpersonal skills (59\%). Most students (52\%) were positive about using Wikis for their project. A survey conducted by Klunder et.al (2009) found that the vast majority of engineering students found that the Wiki was not helpful at all. Students prefer to use word processing software rather than Wikis, because they became confused with multiple edited versions and have difficulties deciphering what their peers were trying to explain. Students also found that Wikis were less organized and time-consuming when trying to find the most current version.

Coyle (2007) conducted a study for junior and senior students in broadcast and communication courses, comparing conventional face-to-face report writing with Wiki-supported writing. Results indicated no difference in the quality of reports between Wikis and face-to-face. Face-to-face collaboration, however, is more efficient in terms of communication among group members and is sometimes preferred because it is familiar. No significant difference existed in students' experiences of learning and community between the two methods. Even though Wiki software provided the editing capability, participants did not edit one another's Wiki work unless they had volunteered and were designated by the group to be an editor. Leong (2009) used Media Wiki as a collaborative platform for a group project in a knowledge management course. Data obtained from the Wiki 1 were analyzed using a combination of quantitative and qualitative methods. This study revealed that limited collaboration is found among the group members in a Wiki learning environment. In addition, despite the potential benefits of using Wikis for course assignments, grading Wikis can pose a challenge to instructors. For example, does the instructor measure the participation of the discussion? Or should grades be based on the actually writing portion of the final document?

Cole (2009) reports on a failed experiment to use Wiki technology to support students with subject matter of a third year undergraduate module. The Wiki had little impact on student engagement simply because the participating students chose not to post to the Wiki. However, a significant level of curiosity expressed by students suggests that the fault lay not with the technology, but with an unattractive course structure design. Aharony (2009) found that students in a knowledge management course contributed mostly in Wiki's discussion section, but not in the contents section. Larusson and Alterman (2009) conclude that a Wikis structure can be cognitively engineered to simplify coordination. Therefore, pre-structuring the Wiki can make Wiki pages function as a coordinating representation for specific recurrent activities among students. Later, this feature will be used to help "engineer" the students' joint focus on particular significant tasks.

From the literature reviewed, the weak connection reported between the Wiki and learning outcomes may be related to the incompletion of the experiential learning cycle, and lack of the coordination in page function. Some of the aforementioned disadvantages in writing group reports using Wikis may be derived from the lack of guidance in Wiki instruction and proper course structure design. Therefore, using Wikis effectively in group report writing for engineering education becomes critical. 


\section{WIKI TECHNOLOGY AND INSTRUCTIONAL THEORY}

The purpose of this study is to propose a formal and well guided structure into Wikis; to investigate how to integrate Wikis into different learning stages; and determine how different features of Wikis reflect the instructional theory. Among the most common instructional theories constructivism and collaborative and cooperative theory are well suited to laboratory learning activities and Wikis function.

\subsection{Constructivism and Kolb model}

Constructivism sees knowledge as constructed rather than given. The critical features are active and manipulative, constructive and reflective, and collaborative and conversational (Park and Choa, 2007). One of many models in Constructivism is the Experiential Learning Model developed by Kolb in 1984 (Kolb Learning Style Inventory 2007), which has been well accepted as an efficient pedagogical model of learning. Kolb suggested that effective learning should include all four stages: Concrete Experience (CE), Active Experimentation (AE), Abstract Conceptualization (AC), and Reflective Observation (RO).

According to Kolb, constructive learning occurs in a two-cyclic learning process. In the first cycle of learning, students conduct the experiment and obtain the raw data. Laboratory report writing is the second experiential learning cycle that actively constructs a high order of learning through consolidating the data, identifying the source of error, provide judgments based upon the results and verifying the laboratory-obtained data with the published data and drawing a conclusion. Wikis are an ideal platform to fulfill the requirements for Constructivist learning environments and turn this deep learning into reality. Students construct their own knowledge as a result of their experiences in the laboratory and interactions with others during the report writing with Wikis.

\subsection{Cooperative and collaborative learning}

The terms collaborative learning and cooperative learning are sometimes used interchangeably. Both promote small group based active student participation over passive, lecture-based teaching. Cooperative learning is usually more structurally defined than collaborative learning (Cooper and Robinson 1997; Smith and MacGregor 1992; Rockwood 1995). In cooperative learning, the instructor is the center of authority in the class, with group tasks usually more close-ended and often having specific answers. In contrast, with collaborative learning, the instructor abdicates his, or her, authority and empowers the small groups, who are often given more open-ended, complex tasks (WCER 2007).

Cooperative learning strategies offer students an opportunity to learn from and with other students. The laboratory section itself is a cooperative learning process where students learn from each other with a focused topic. Cooperative teams achieve higher levels of thought and retain information longer than students who do their work individually (Johnson and Johnson 1986). Wikis extend this cooperative learning further by sharing and creating knowledge online in a virtual class. The collaborative features of Wikis make them particularly well suited for cooperative learning environments (Park and Choa 2007).

Collaborative learning is more powerful in the sense that it takes place in the context of a community of practice in Wikis. Wikis can serve as a knowledge platform for a community of practice where community members can share their knowledge with the group, put up interesting pieces of information, work together, discuss issues, etc. (Park and Choa 2007).

Wikis are characterized by some of the fundamental elements of social networking such as sharing ideas and socially constructing knowledge. Therefore, if the purpose of the laboratory reporting is to enhance student experiential learning from the laboratory or lecture, sharing alone is not enough. Cooperative approaches have to take place in the Wiki to guide students to construct and reflect the knowledge from the laboratory-obtained data. This study takes the Wiki as an infrastructure of the collaborative learning and integrates a scaffolding structure as the element of the cooperative learning into the Wiki. 


\section{METHODS}

This study proposes a scaffolding structure in Wikis that guides students to develop report documents for the laboratory or group project. Under this scaffolding structure, students are tasked to write individual sections for the group report based on, or connected to, other members' written sections. This kind of interconnected activity during the report writing process extends the collaboration from the laboratory session to report writing, allowing students to reach a level of in-depth learning through peer editing and collaboration. The proposed scaffolding structure for Wikis is hypothesized to promote peer-to-peer interaction during report writing and enhance the experiential learning cycle. A Mechanical Engineering Technology Laboratory was used as a case study to implement the scaffolding structure in group report writing using Wikis. Data was collected to analyze student collaborative writing using scaffolding structure. A survey was conducted to assess the outcome.

\subsection{Scaffolding structure}

In order for students to experience the high order learning cycle, students are required to develop and load a relevant report section into the predetermined scaffolding structure in different stages as the laboratory report proceeds. The scaffolding levels are designed identically to the subtitles of the laboratory report. The recommended subtitles of a laboratory report are structured as follows; Introduction, Methods, Results, Analysis, Conclusion, and Appendix. Students report contents in Wikis are developed and uploaded in a different sequence from normal subtitles. The report sections are uploaded in the following sequence; Appendix, Method, Results, Analysis, Introduction and Conclusion. The laboratory-obtained results are the first fundamental parts to upload into a Wiki for all team members to view, process, and analyze.

Table 1 Scaffolding structure for laboratory report in Wiki

\begin{tabular}{|l|ll|}
\hline \multicolumn{1}{|c|}{ Report sections } & \multicolumn{1}{c|}{ Report sections in a scaffolding structure } \\
\hline 1.Introduction & Level 6 & "Conclusion" submitted by Group \\
\hline 2.Methods & Level 5 & "Introduction" submitted by Student D \\
\hline 3.Results & Level 4 & "Analysis" submitted by Student C \\
\hline 4.Analysis & Level 3 & "Results " submitted by Student B \\
\hline 5.Conclusion & Level 2 & "Methods" submitted by Student A \\
\hline 6.Appendix & Level 1 & "Appendix" submitted by Group \\
\hline
\end{tabular}

Table 1 illustrates the concept of the scaffolding structure. The first column in Table 1 lists the subtitles of the laboratory report, and the second column illustrates the upload sequence for team members. The Appendix is the first report section uploaded as the base of the structure, followed by Methods, Results, Analysis, Introduction and finally the Conclusion.

Level 1 Appendix

Test results from the laboratory session provide students with the foundation for scaffolding structure. By the end of the laboratory, students are required to upload all raw data, including photos of the equipment, to the designated Wiki page under the Appendix. While a student uploads the data into the Wiki, some missing data could be spotted, which will allow students to redo the test. Students also discuss the role of writing a report after the laboratory.

Level 2 Methods

The next stage involves describing the testing standard, equipment and process that lead to the laboratory results. This could be arranged after the laboratory as long as students measure sample size during the laboratory session and are familiar with testing standards.

In levels 1 and 2, students move from Kolb's active learning experimentation in the laboratory session to the Concrete Experience (CE) and Reflective Observation (RO) in reporting stages by collecting tested results and reflecting on the associated method and sample details. 
Level 3 Results

The results section summarizes the data and information listed in the Appendix, such as mean and standard deviation of the raw data, as well as addresses the source of error. Students working in the results section often learn how to process and consolidate raw data to present corrected data in a clearer way.

Level 4 Analysis

Students are expected to interpret the results and make hypotheses, verify the results with the published data, and integrate the consolidated results with their own perceptions. In levels 3 and 4, students complete the learning cycle of Reflective Observation (RO) by consolidating all experiment results, making judgments, and comparing published data with their tested data.

\section{Level 5 Introduction}

Students have the opportunity to experience Abstract Conceptualization (AC) through reviewing the engineering concepts and goals of the laboratory as well as the samples details in the introduction section. Students focus on how the experimentally derive data from the laboratory connects to the theoretical framework at the Abstract Conceptualization (AC) stage of the learning cycle.

\section{Level 6 Conclusion}

In the Conclusion section, students' participation in co-writing this section is mandatory in order to fulfill the Active Experimentation (AE). Students are expected to consider opinions of other group members and integrate these conclusions into their own findings. Students are also expected to provide judgment with reference to published data and verify the hypotheses made in Level 4. Finally, students summarize overall findings and describe what they have learned from the laboratory.

All team members are required to complete final peer editing before the deadline. The process helps students experience the entire learning cycle in a manipulative way. Participating in review and editing other group members' work leads to more ownership of knowledge for all team members due to multiple involvements in the learning cycle as opposed to a final edit completed by only one student.

\subsection{Participants}

Collaborative report writing using Wikis was introduced in the 2010 academic fall and winter quarter as a pilot study to support the teaching of the Mechanical Engineering Technology Plastic Laboratory II (MET Lab II). MET Lab II is a laboratory-based course consisting of seven laboratory assignments related to plastics during the course of ten weeks. The course is designed to have students apply knowledge from a concurrently running MET-II lecture (a five-week lecture) to the actual laboratory experiments. The laboratory is conducted with a group of four students, collecting the laboratory data during the two-hour laboratory period. Six groups with a total of 24 students participated in the pilot study. After the laboratory session, the group has two weeks to submit the compiled laboratory report that documents the data and analysis. In addition to laboratory reports, group members are tasked to collaborate on writing a comprehensive research report about sustainable plastic packaging.

\subsection{Procedure}

The scaffolding structure and group report format were presented together to students on the first day of class in the laboratory. The Wiki used at Rochester Institute of Technology is Dashboard Wiki and can be accessed through My Courses, which links to the MET Lab II Wiki webpage.

\subsubsection{Set up the Wiki page}

Before the class started, the instructor assigned students into groups and set the permission to access the report page. Figure 1 demonstrates the assignment of the laboratory groups and access permission. 


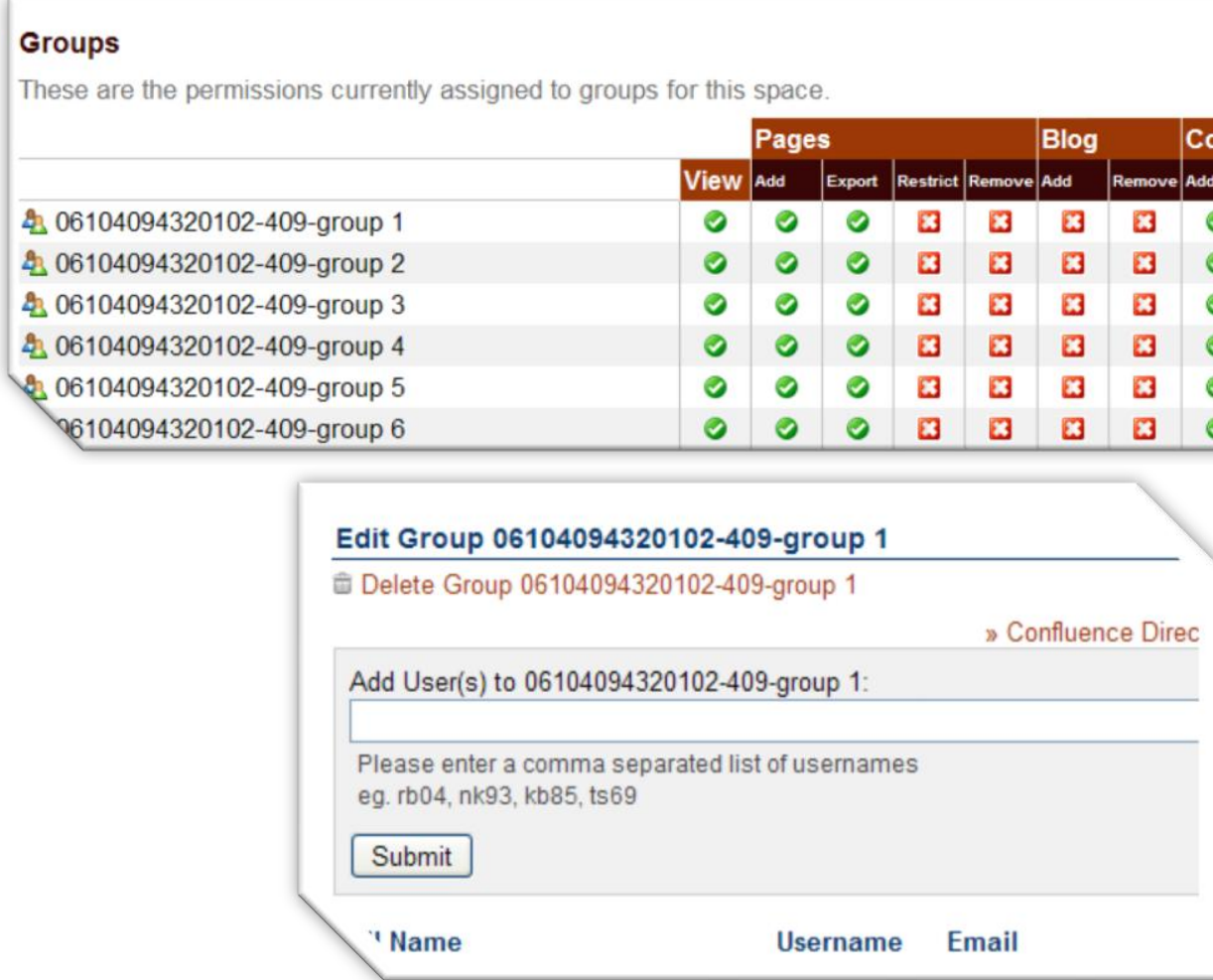

Figure 1 Assignment of the groups and the access permission

The Wiki home page contains each laboratory group's page, course outline and relevant testing standards as well as the reference website (Figure 2). A student's access to the report page is limited only to his, or her, own group.

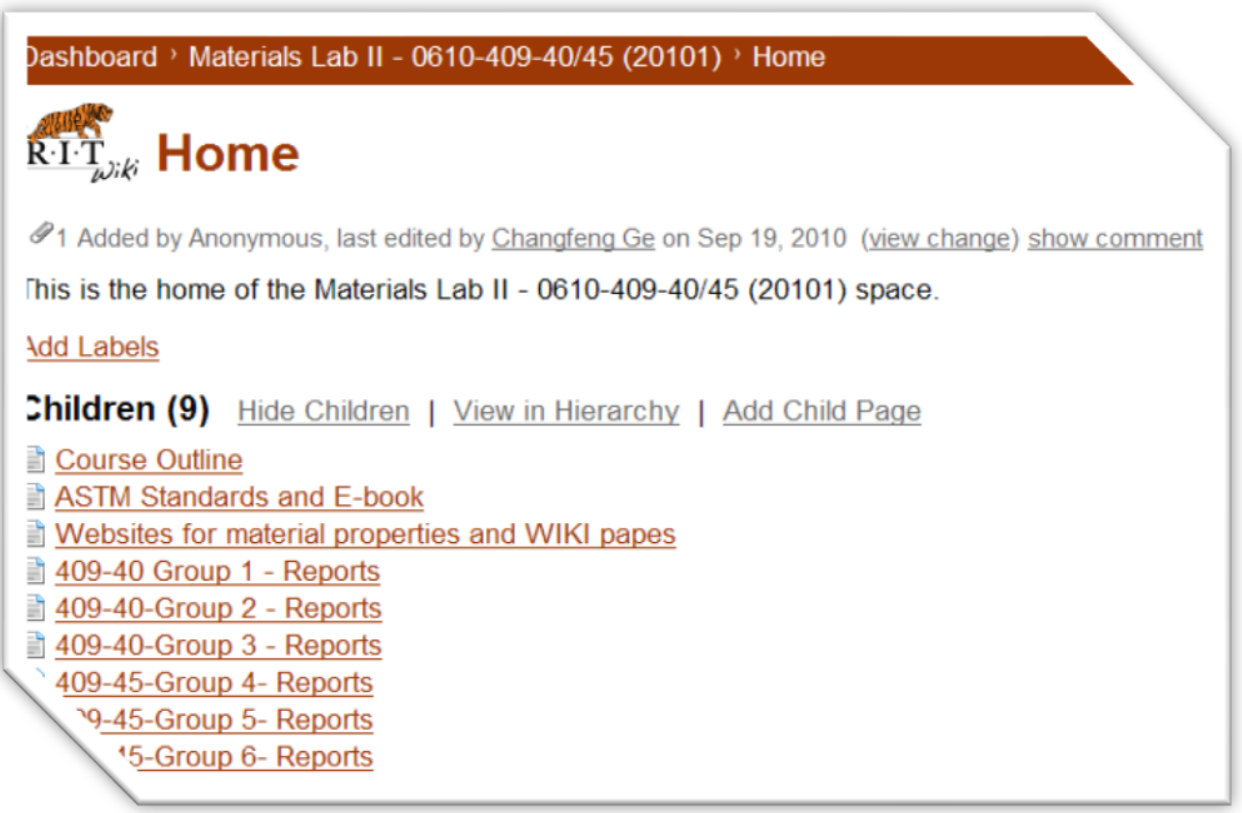

Figure 2 The home page of MET Lab II 


\subsubsection{Develop the report based upon the scaffolding structure}

The team leader first adds students' names next to the subtitles of the Wiki report page, which reminds team members about their designated report section and upload sequence. When students forget to submit their portion in the Wiki, the other team members have difficulty continuing their report writing. For example, if a student is tasked to put the test results together, but fails to submit the consolidated Results section in the Wiki on time, the next student who writes the Analysis section has to wait until the Results part is posted. This delays the report and results in a late submission. In order to overcome this problem, the "Watch" function in Wiki is set up to send an email to students when there is a change in report content and reminds the student to submit the next required documents into the Wiki (Figure 3).

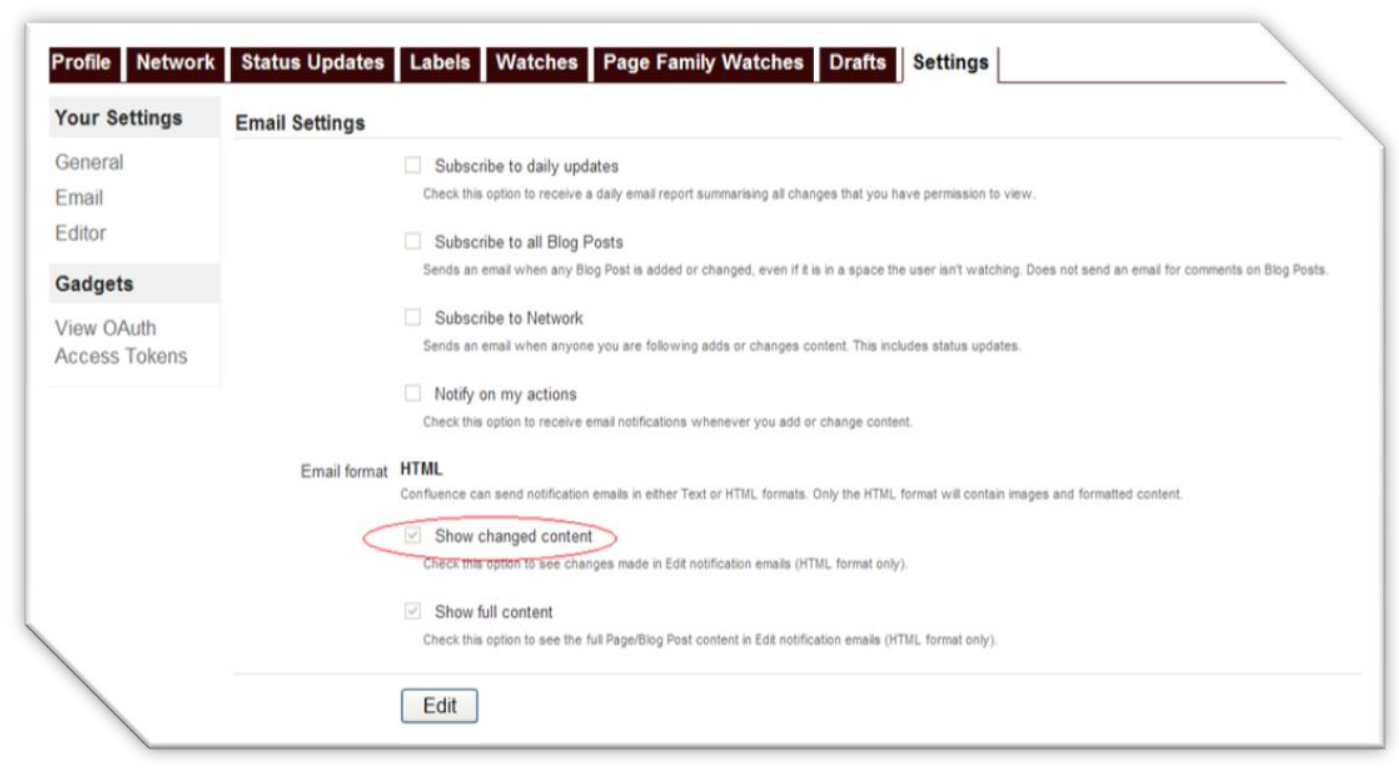

Figure 3 Watch settings in WIKI

Each group page is connected to report pages. These group report pages have report templates with Introduction, Methods, Analysis, Conclusion and Appendix that scaffold a student's report writing. After the laboratory, students are asked to upload all handwritten results or spreadsheets onto the website, which serves as the basis of report writing as well as the report Appendix. Students then develop the report by submitting the assigned sections to the Wiki in sequence.

Figure 4 shows the Wiki page of a water absorption test featuring three different melted plastic resins sandwiched between two glass slides, which is posted under the Appendix at Level 1 as well as the Methods section at Level 2. The remaining report sections are not yet completed. Because of the pre-arranged upload sequence, progress depends on group member's contribution. When all report contents are developed and uploaded, team members are required to edit the group report, including peer report sections. 


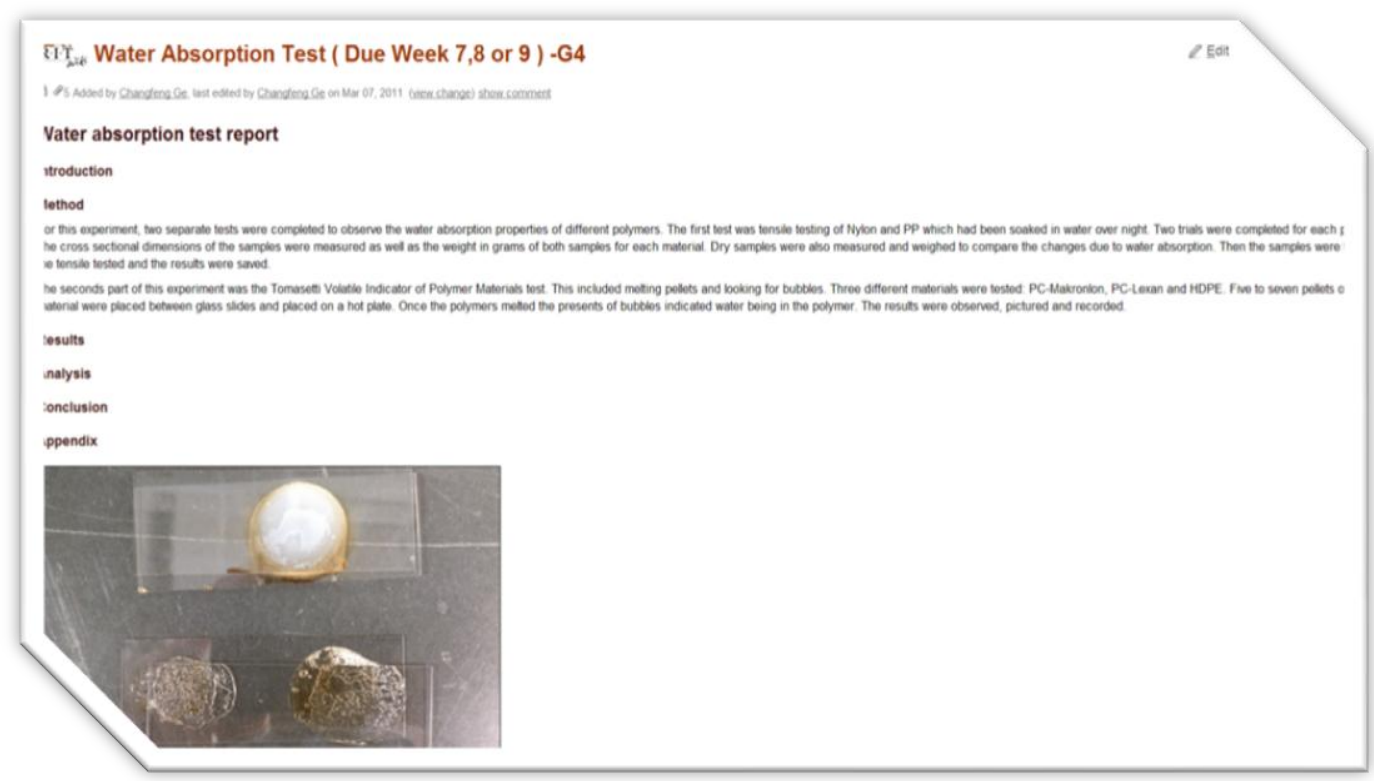

Figure 4 Laboratory report in the process of construction at Level 1 Appendix and Level 2 Method

\subsubsection{Grading the report in Wiki}

A sample rubric for a laboratory report in the table below was developed for MET II to assess the individual laboratory report that is posted as Wiki comments from the report (Table 2). The rubric is designed to mirror all components stated in Table 2 to achieve high order learning through report writing. The final grade is based on three components: reports of the laboratory, performance in the laboratory, and contribution to report writing and pre-laboratory quizzes. The contribution to report writing is based on the interaction between students during the development of the report that can be traced by the historic pages.

Table 2 Laboratory report rubric

\begin{tabular}{|l|}
\hline Laboratory report rubric \\
\hline Title \& Abstract \\
\hline Summarizes a sense of the full report concisely and effectively \\
\hline Introduction \\
\hline Establishes the scientific concept of the laboratory \\
\hline Effectively presents the objectives of the laboratory \\
\hline Briefly presents the sample \\
\hline Methods \\
\hline Gives enough details to allow for replication of procedure \\
\hline Gives details of sample materials, standard, and apparatus \\
\hline Results \\
\hline Presents data clearly and accurately \\
\hline Indicates the possible source of error \\
\hline Statistically presents the data if more than one sample was used \\
\hline Analysis \\
\hline Provides logical explanation for the derived data \\
\hline Provides judgment with reference to published data \\
\hline Conclusion \\
\hline Opens with effective statement of overall findings \\
\hline Describes what has been learned \\
\hline Presentation of the report \\
\hline Written in scientific style: clear and to the point \\
\hline Correct grammar and spelling \\
\hline Citations and references adhere to proper format \\
\hline
\end{tabular}


Figure 5 shows history pages that allow instructors to restore the report version edited by different students. Because each student deals with different amounts of information and report contents in report writing, a grade rubric was developed to take the difference into account.

Grade $=$ (Individual performance factor) $\mathrm{x}$ (Laboratory report grade-group)

$\begin{array}{lll}(0 \text { to } 110) & \text { (0.8 to } 1.1) & \text { (0 to 100) }\end{array}$

The performance factor consists of laboratory report contribution and performance in the laboratory as well as the quizzes. The report writing contributed by an individual team member can be measured by editing activities in the Wiki. The performance in the laboratory session is based upon instructor's observation in the following criteria: Team work, role rotation, testing procedure and laboratory safety.

\subsection{Data collection}

The Wiki Dashboard automatically tracks contributions made by each group member through historic pages (Figure 5 and 6). By using the historic pages and the comment platform, data can be collected, including the contents of each member, over a period of time, and the flow of the topics of discussion by each group member can be tracked.

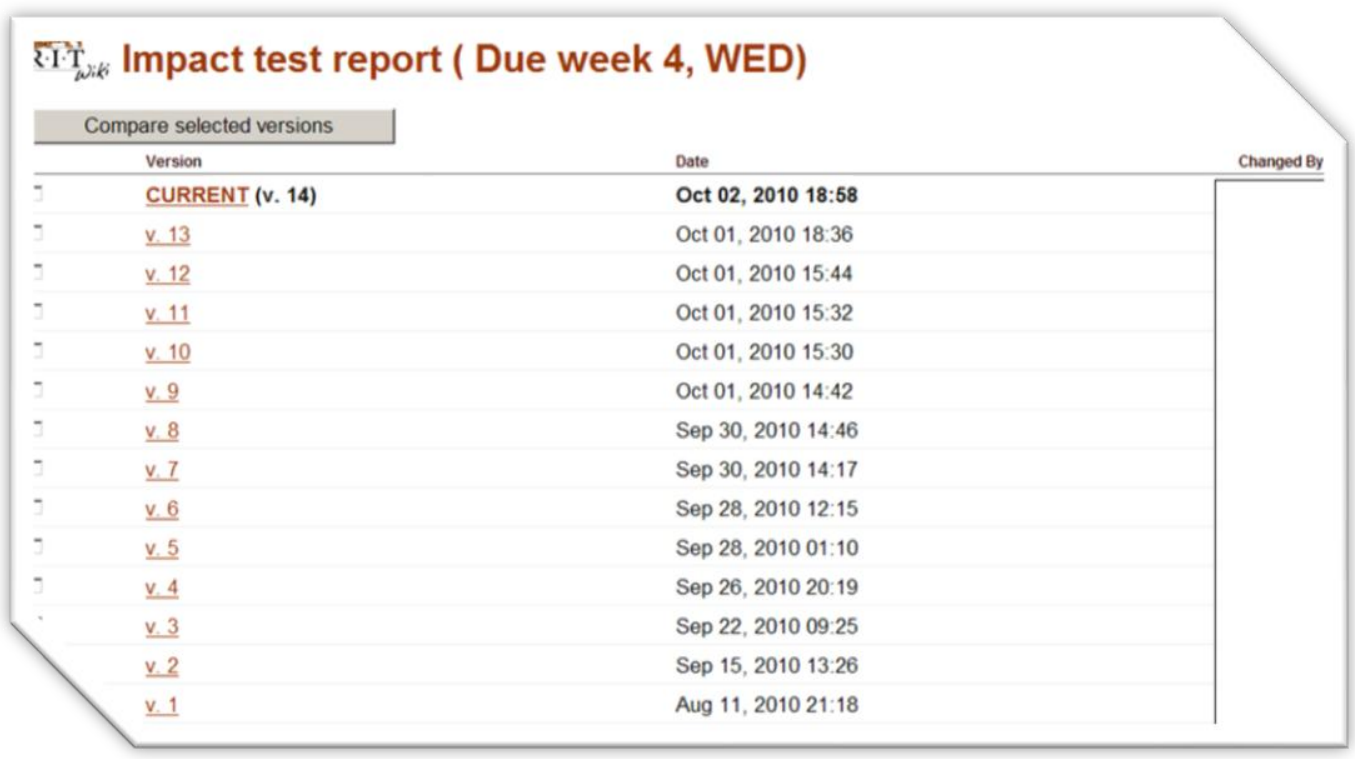

Figure 5 History pages of the group laboratory report 


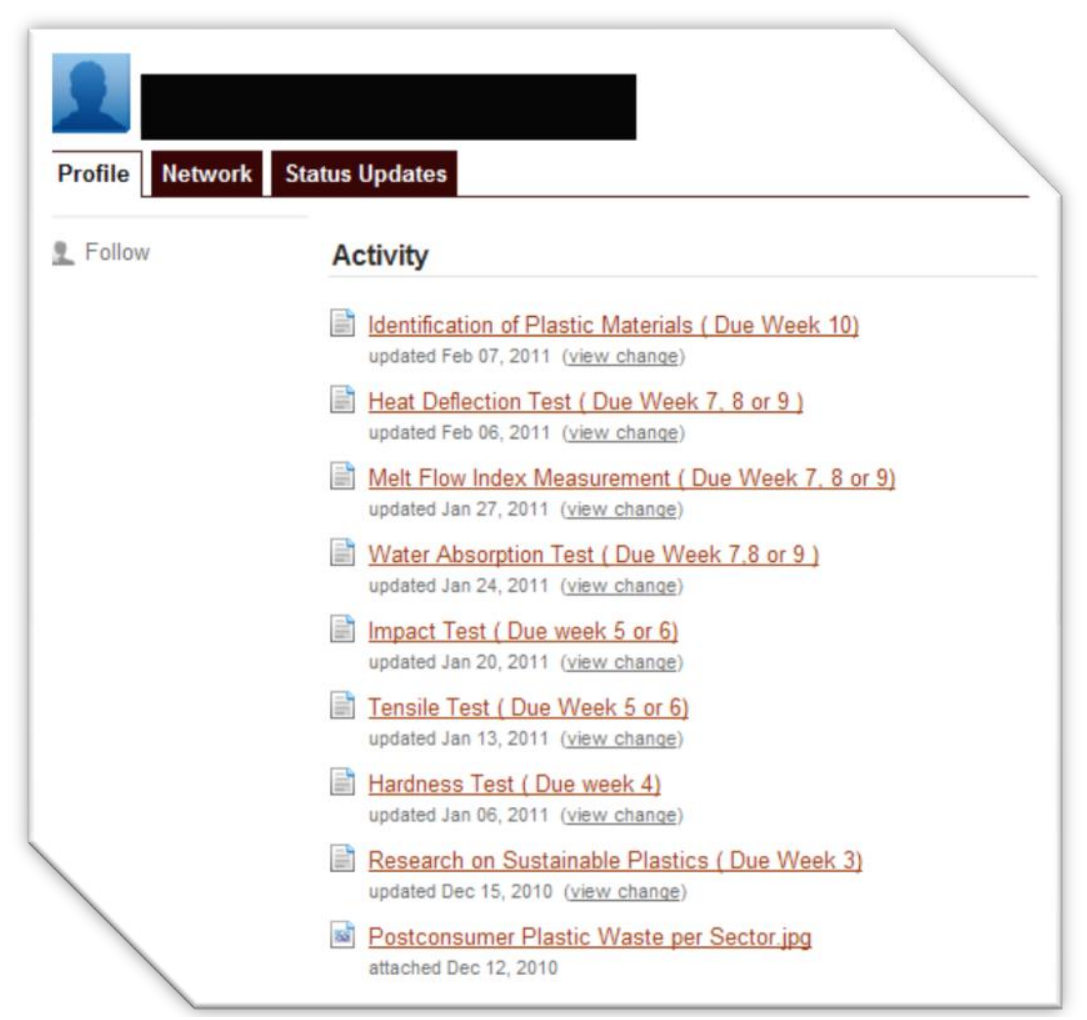

Figure 6 Summary of a student's contributions to report writing during the entire quarter

In addition, a survey is conducted in the final week. It includes 10 questions scored on five-point scales ranging from "strongly agree" (score $=5$ ) to "strongly disagree" (score $=1$ ) and three open-ended questions asking students to reflect on the advantages and disadvantages they experienced in collaborating through a scaffolding Wiki webpage in comparison to the conventional collaboration such as email and face-to-face.

\section{FINDINGS AND DISCUSSION}

\subsection{Distribution of laboratory report activities}

Students in groups of six were given two weeks to complete the laboratory report in the Wiki after the laboratory session. Each group had seven laboratory reports to write. Figure 7 combines the report activities of six groups into 42 laboratory reports. The work and collaborative activities are recorded in the Wiki history pages and measured as edit and upload times into the relevant report sections. From the data presented in Figure 7, it can be determined that many groups had no writing activities until two days prior to the due date. Some laboratory reports were completed within two to three days; right after the laboratory session was over. It is also noted that during the course of 10 weeks time, the closer the end of the quarter was approaching, the collaborative writing time tended to shorten. The average non-activity days over a course of 14 days are as follows: 10 days for group 1,9 days for group 2, 10 days for group 3, 9 days for group 4, 10 days for group 5 and 10 days for group 6. Students worked the most four to five days either before the deadline or right after the laboratory session, which leads to the suggestion that a 14 day report writing time could be shortened to seven days in order to keep the content flowing smoothly during the report writing. This finding is partially in agreement with the Wiki-based project reporting (Leong 2009). 


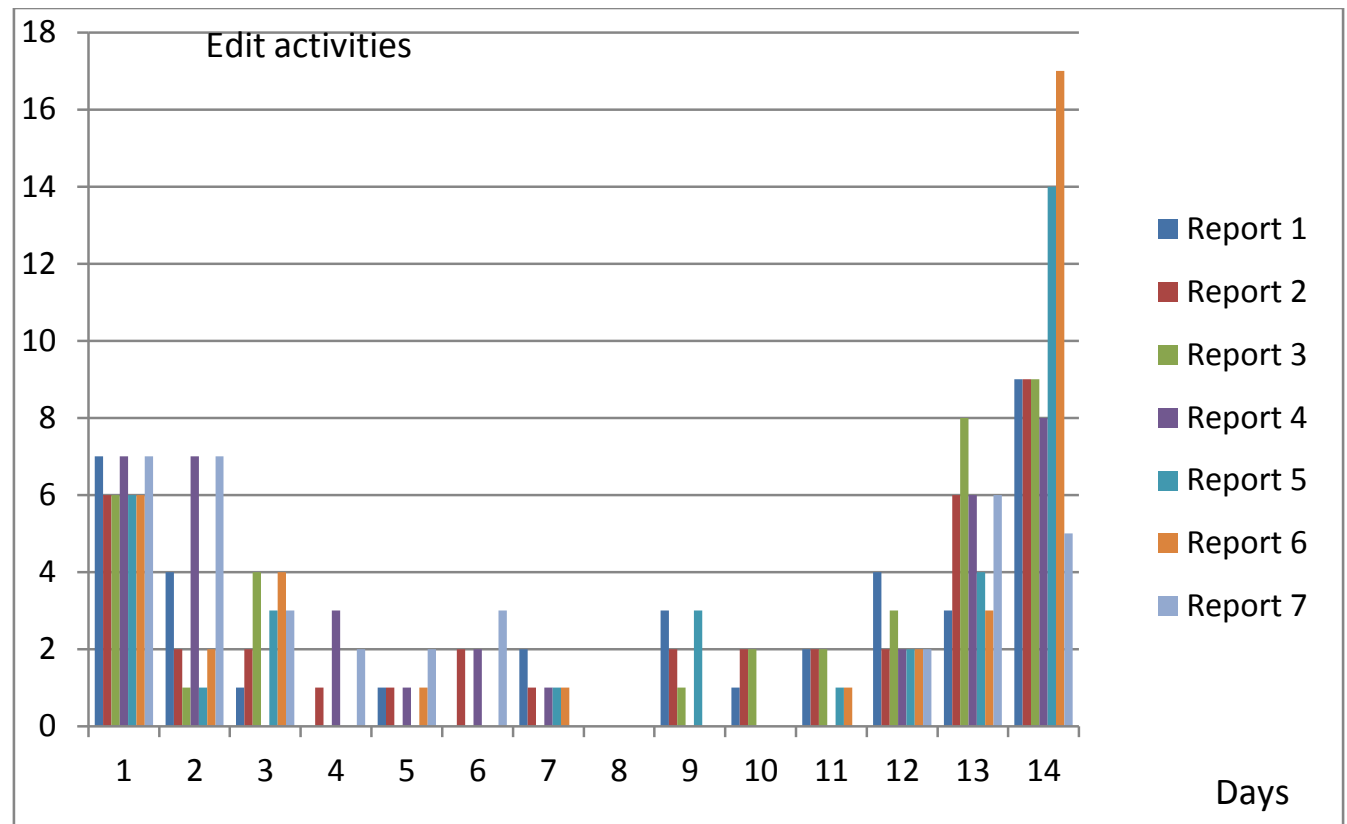

Figure 7 Distribution of laboratory report activities

An interesting finding from this research is that the quality of the actual writing of the final report does not correlate to the editing activities. Some students have significant numbers of times editing, i.e. $\log$ in and $\log$ out, but not many actual edits. Some students edited several times, but developed the quality portion of the writing. Although the Wiki used in this study does not measure the file size of contribution from each member, the amount of works can be traced back.

The Wiki made it easy for the instructor to review and grade students' reports online, particularly in the case of laboratory report-intensive classes like the case study where students' grades are averaged from multiple laboratory reports grades. By using a Wiki-supported laboratory, the instructor was able to verify data and find a website by clicking the reference link. In the past, the instructor had to email the rubric to all group members. Together with the rubric (Table 2), the instructor was able to convey the message to the group for students to reflect on comments in the next report writing.

In the past, grading laboratory reports was a big part of the instructor's workload; with the help of the Wiki, grading based on the Wiki platform is much more productive as it reduces the lead time between grading and posting the grade. In addition, calculating the final grade based on writing report, performance in the laboratory session and quizzes, worked fairly well. Often, students who failed to participate in the laboratory still participated in laboratory report writing. These students receive a partial grade based on their contribution to report writing in the Wiki. In the pilot study, all students participated in the report writing, reviewing and editing. There were no student complaints about team members who failed to contribute to the report writing.

\subsection{Student engagement in laboratory session}

Two problems observed in the past that cannot be solved effectively using existing technology and tools were that students took turns writing the laboratory reports, and they complained about the unequal contribution at the end of the quarter. Since the implementation of the Wiki, these two problems disappeared instantly. Students had to connect with each other in the Wiki in order to develop the report as they rely on each other's data, or information, to write their own section. The scaffold Wiki is a virtual classroom without an instructor where students have to show up in the class (Time they logged in) and do a decent job of writing (quality contents and words).

Another interesting finding is that students who missed the laboratory session turned to their team members requesting a makeup laboratory demo in order for them to write the portion assigned. It became normal practice, 
when one laboratory session was over, a student demonstrated to another team member, who either missed the previous laboratory session, or needed to recapture what the team did in the last laboratory.

During the construction of the scaffold report within the Wiki, students showed consistent interaction with their peers in order to understand each other's work in relation to laboratory results. The scaffolding structure guided students to produce their own contribution based on other member's input. Wikis promote collaborative behaviors among students beyond the laboratory session, which leads to a high order of learning.

\subsection{Student's feedback}

Twenty-one out of twenty-four students took the survey. From Table 3, students agreed strongly that the Wiki helped to exchange the data and findings more easily (Mean $=3.95)$ and monitor each other's efforts more clearly (Mean $=4.19$ ). Students agree strongly that scaffolding structure in laboratory report writing is useful (Mean $=3.905$ ). The lowest score went to the questions regarding the usefulness of the scaffolding structure in writing a research report $($ Mean $=3.00)$. Students responded that participating in the review and editing process helped them with learning (Mean=3.762). Students responded that the pre-laboratory quizzes did help them do better in the laboratory, and the rubric posted in the Wiki helped to improve laboratory report writing overall.

Table 3 Collaboration survey scores by scaffolding Wiki

\begin{tabular}{|c|l|c|c|}
\hline S/N & \multicolumn{1}{|c|}{ Questions } & Mean & SD \\
\hline 1 & Wiki helped us to exchange data and findings more easily & 3.952 & 0.921 \\
\hline 2 & Wiki helped us monitor each other's work more clearly & 4.190 & 0.750 \\
\hline 3 & Wiki supported me in research report writing and presentation & 3.000 & 1.049 \\
\hline 4 & Wiki helped us to distribute the work load better and fairly & 3.571 & 0.926 \\
\hline 5 & Wiki helped me better define my role in the group & 3.286 & 0.644 \\
\hline 6 & Scaffolding structure in laboratory report writing in Wiki was useful & 3.905 & 0.944 \\
\hline 7 & Scaffolding structure in research report writing in Wiki was useful & 3.619 & 0.973 \\
\hline 8 & Participating in reviewing and editing other's work helped me in learning & 3.762 & 0.700 \\
\hline 9 & The Wiki-based laboratory rubric helped us overall in improving the report writing & 3.714 & 0.956 \\
\hline 10 & The pre-laboratory quizzes helped me do better in the laboratory & 3.429 & 0.811 \\
\hline
\end{tabular}

In responding to the open ended questions in the survey, all students remarked that the scaffolding structure for laboratory reports was very helpful when writing a laboratory report. Students found that the scaffolding structure for laboratory report writing was well designed, efficient and worked well in report writing. However, the scaffolding structure for research reports was somewhat confusing and needs to be improved.

Most students responded very positively when comparing conventional group report writing with scaffolding Wiki-supported laboratory report writing. Students found that the Wiki made the reporting process easy for them to write, review and hand in the laboratory report in a single platform. Overall, the surveys received positive feedback and proved the hypothesis that the scaffolding structure in the Wiki enhanced experienced learning.

\subsection{Laboratory report assessment}

Using Wikis for laboratory reporting, the instructor provides students with a more fair and adequate assessment based on the quality and quantities recorded by the Wiki. With the Wiki historic pages, the instructor can provide each student with feedback on the report immediately after the first report is uploaded, and the instructor can correct the course of the report development when necessary. The peer evaluation, however, is mostly conducted by the final week and has no impact on improvement in writing. Wikis made it easy for instructors to collect the data effectively, such as the quality and quantities of the writing, which allows instructors to evaluate and analyze the data and develop an adequate teaching strategy. 


\subsection{Drawbacks}

The drawback found by the instructor mostly relates to writing and formatting the laboratory reports. In order for the instructor to know students' names and the sections they wrote, the instructor had to trace back all history pages one by one, which is tedious work. It would be more efficient if a student's particular section was highlighted in the final report; the instructor would then know who wrote and edited the particular part of the laboratory report. Also, in the Wiki page, the comments and corrections made on the laboratory report by the instructor were not obvious and highlighted due to limited choices of the text color and style. A review function similar to those used in PDF and Microsoft Word would be helpful. From the instructor's point of view, the advantage of a Wiki-supported laboratory far outweighs the disadvantages.

All students expressed that formatting and uploading the tables and pictures were the two major drawbacks. Students are familiar with word processing tools, and it is very difficult for them to upload the pictures and tables that are not properly displayed in the Wiki page. Students report their hope that the Wiki can be designed similar to Microsoft Word to improve the software infrastructure. In addition, the Wiki does not allow two people to edit the same file at the same time. Students also responded that most of the time when they used the Wiki, the cursor did not display. Another area for improvement is the Watch function. The Watch function in Wiki requires students to register at the beginning of the quarter and activate the Watch function. Not every student registers and activates the Watch function. Therefore, if an easy click was available to allow the student who just completed his or her part of the report to send an email to the next student, the entire process would be simplified.

Overall, when comparing other surveys conducted on Wiki, the Wiki in this study received positive feedback thanks to the laboratory-results-based scaffolding structure.

\section{CONCLUSION}

When comparing the preliminary findings and results of this study to previous studies on Wikis in engineering education, the Wiki in this case study demonstrated a positive impact on student learning due to the scaffolding structure introduced. The study verifies that a strong connection between learning outcome and Wikis could be achieved by integrating cooperative element such as scaffolding structure into Wiki's collaborative infrastructure. Instructors need to develop a more coordinated scaffolding structure for an on line course in order for students to effectively construct a high order of learning through writing report.

The Wikis with the scaffolding structure are particularly useful in laboratory report-intensive classes where students' grades are averaged from multiple laboratory report grades. The Wikis greatly reduced the time the instructor needed for lead time and to grade the report. A Wiki rubric for reporting is necessary in conjunction with Wikis as it sets a clear performance expectation in each of the laboratory report sections, and focused more on what contents were posted in the designated report section rather than counting the log-in times to the Wiki.

The Wiki with scaffolding structure is recommended to apply to other engineering and science disciplines, in addition to mechanical engineering, such as chemical engineering, electrical engineering and other science majors where students acquire knowledge through hands-on experiential learning.

The future study should be conducted involving more students of different demographics in different engineering and science disciplines. A post-report quiz needs also to be added on to the study to compare the learning outcome before and after the report writing in wiki.

\section{ACKNOWLEDGMENT}

The study has been supported by the Wallace Center at Rochester Institute of Technology. 


\section{AUTHOR INFORMATION}

Dr Changfeng Ge is an Associate Professor at the Rochester Institute of Technology. He received his doctor of engineering degree from the University Dortmund, Germany. His prior international work experiences include working as engineer at the VDZ GmbH, Germany, Senior Engineer ( R\&D) at the Singapore Institute of Industrial Research and Technical Director of the Pack Solutions Pte Ltd. E-mail: cfgmet@ $@$ rit.edu

\section{REFERENCES}

1. Aharony, N., 2009. The Use of a Wiki as an instructional tool: A Qualitative Investigation, Journal of web librarianship, 2(1), 35-53.

2. Cole, M., 2009. Using Wiki technology to support student engagement: Lessons from the trenches, Computers and Education, 52, 141-146, doi:10.1016/j.compedu.2008.07.003,

3. Cooper, J. and Robinson, P., 1998. Small group instruction in science, mathematics, engineering, and technology, Journal of College Science Teaching 27,383-388

4. Chao, J., 2007. Student project collaboration using WIKI, $20^{\text {th }}$ Conference on Software Engineering Education \& Training (CSEET'07), IEEE Computer Society.

5. Coyle, J. E. Jr., 2007. WIKIS in the college classroom: A comparative study of on line and face-to-face group collaboration at a private liberal arts university, Dissertation at Kent State University College and Graduate School of Education, Health and Human Services.

6. Cubric, M., 2007. WIKI based process framework for blended learning, WIKI Symposium 2007, Montreal, Canada.

7. Parker, K. and Chao, J., 2007. Wiki as a teaching tool. Interdisciplinary Journal of Knowledge and Learning Objects, 3, 57-72.

8. Duffy P. \& Bruns A., 2006. The use of blogs, wikis and RSS in education: A conversation of possibilities. Proceedings of the Online Learning and Teaching Conference 2006, Brisbane.

9. Elgort, I., Smith, A. G. and Toland, J., 2008. Is wiki an effective platform for group course work? Australasian Journal of Educational Technology, 24(2), 195-210.

10. Elliott, E. W. III and Fraiman, A., 2010. Using Chem-Wiki to Increase Student Collaboration Through Online Lab Reporting, Journal of Chemical Education, 87(1), 54-56.

11. Goodsell, A. S., Maher, M. R., and Tinto, V., Eds., 1992. Collaborative Learning: A Sourcebook for Higher Education. National Center on Postsecondary Teaching, Learning, \& Assessment, Syracuse University.

12. Hazari, S. and North, A., 2009. Investigating Pedagogical Value of Wiki Technology, Journal of Information Systems, 20(2), 187-198.

13. Heys, J. J., 2007. Group Project in Engineering using a WIKI, Proceedings of the 2007 ASEE Annual Conference.

14. Johnson, DW, Johnson RT and Smith, KA., 1991. Cooperative learning: Increasing college faculty instructional productivity, School of Education and Human Development, George Washington University (Washington, DC).152p.

15. Kessler, G., 2009. Student initiated attention to form in WIKI-based collaborative writing, Language Learning \& Technology, 13(1), 2009, 79-95. Available at URL http://ltt.msu.edu/vol13num1/kessler.pdf

16. Khandanker, N. and Soh, LK., 2009. Classroom WIKI: A collaborative WIKI for instruction use with multiagent group formation, IEEE Transaction on Learning Technologies, TLT-2009-07-0129.

17. Klunder,N, Kam AE, van der Laaken BMD. and Post,PC.,2009. Collaborative Wiki-Writing for Engineers. Fun or Failure? Available at URL http://www.sefi.be/wp-content/abstracts2009/Klunder.pdf

18. Kolb Learning Style Inventory, 2007. Hay Group Transforming Learning.

19. Lab Write, 2004. Available at URLhttp://www.ncsu.edu/labwrite/instructors/excelsheets.htm, Copyright NC State University.

20. Larusson,.J..A. and Alterman, R., 2009. Wikis support the "collaborative" part of collaborative learning, Computer-supported collaborative learning, 4,371-402; DOI 10.1007/s11412-009-9076-6.

21. Leong, K., 2009. Using Wiki for collaborative learning: a case study of an undergraduate student's group project, the International, Conference on Knowledge Management 2009 at the University of Hong Kong.

22. Macgregor, J., 1990. Collaborative learning: Shared inquiry as a process of reform, The changing face of college teaching, New Directions for Teaching and Learning, 42,19-30; DOI: 10.1002/t1.37219904204. 
23. Maha, AY., 2009. Using Wikis to Support Teamwork Skills in Software Engineering, 22nd Conference on Software Engineering Education and Training; DOI: 10.1109/CSEET.2009.30.

24. McGaughey, A. J. and Michalek, J. J., 2008. Wiki-Based Learning in the Mechanical Engineering Classroom, ASEE Annual Conference 2008.

25. Moskaliuk, J., Kimmerle, J. and Cresst, U., 2009. WIKI-supported learning and knowledge building: effects of incongruity between knowledge and information, Journal of Computer Assisted Learning, 25(6), 549-561.

26. Puente, X. D. P., 2009. New method using WIKIS and forums to evaluate individual contribution in cooperative work while promoting experiential learning: Results from preliminary experiences. IEEE Transaction On Learning Technologies, TLT-2009-07-0129.

27. Pusey, P. and Meiselwitz,G.,2009. Heuristics for Implementation of Wiki Technology in Higher Education Learning, Online Communities and Social Computing, 5621/2009, 507-514; DOI: 10.1007/978-3-64202774-1_55.

28. Rockwood, H. S. III, 1995. Cooperative and collaborative learning, The National Teaching \& Learning Forum, 4(6), 8-9.

29. Rockwood, H. S. III, 1995. Cooperative and collaborative learning, The National Teaching \& Learning Forum, 5(1), 8-10.

30. Šerbec, I.N.O., Strnad, M. and Rugelj, J., 2010. Assessment of WIKI-supported collaborative learning in higher education, Proceedings of the $9^{\text {th }}$ International Conference on Information on Technology based Higher Education and Training: IEEE Press, Piscataway, NJ, USA.

31. Wahed, M. A. and Nagy, Z. K., 2009. Applying Kolb's experiential learning cycle for laboratory education, Journal of engineering education, 98(3), 283-294.

32. Universität zu Köln. Constructivism. Available at URL http://methodenpool.unikoeln.de/situierteslernen/fenwick3.pdf

33. WCER, 2007. What's the difference between collaborative and cooperative learning? Available at URL http://www.wcer.wisc.edu/archive/cl1/cl/question/TQ13.htm

34. Zorko,V., 2009. Factors affecting the way students collaborate in a WIKI for English language learning, Australia Journal of Education Technology, 25(5), 645-665. 


\section{NOTES}

